\title{
BIOSORPTION OF CATIONIC DYES BY1, BY2 AND BG4 BY MOSS Rhytidiadelphus squarrosus FROM BINARY SOLUTIONS
}

\author{
LUCIA REMENÁROVÁ ${ }^{1}$, MARTIN PIPÍŠKA ${ }^{1,2}$, \\ MIROSLAV HORNÍK ${ }^{1,2}$, JOZEF AUGUSTÍN ${ }^{1,2}$ \\ ${ }^{I}$ Department of Biotechnology, University of SS. Cyril and Methodius, J. Herdu 2, \\ Trnava, SK-917 01, Slovak Republic (pipiskam@ucm.sk) \\ ${ }^{2}$ Consortium for Environmental Biotechnology and Environmental Chemistry, \\ Hlavná 418, Špačince, SK-919 51, Slovak Republic
}

\begin{abstract}
A biosorbent prepared from moss Rhytidiadelphus squarrosus biomass was used for biosorption of cationic dyes - Malachite green (BG4), Auramine O (BY2) and Thioflavine T (BY1) from binary aqueous solutions. Sorption data obtained at non-equilibrium conditions were analyzed by SheindorfRebuhn-Sheintuch (SRS) equation (competitive model for binary systems derived from Freundlich isotherm) and extended model of Freundlich isotherm. Following the comparison of coefficient of determination values $\left(\mathrm{R}^{2}\right)$ as well as values of root mean squared error (RMSE), the extended model of Freundlich isotherm was more suitable for description of investigated binary systems BG4-BY1 $\left(\mathrm{R}_{\mathrm{BG} 4}^{2}=\right.$ $\left.0.983, \mathrm{R}_{\mathrm{BY} 1}^{2}=0.993\right)$ and BG4-BY2 $\left(\mathrm{R}_{\mathrm{BG} 4}^{2}=0.976, \mathrm{R}_{\mathrm{BY} 2}^{2}=0.995\right)$. The competition coefficients $a_{i j}$, obtained from SRS model can be considered as a way to quantify mutual competitive interactions. The competition coefficients indicated that the presence of BY1 in binary system decreased the sorption of BG4 $\left(a_{B Y 1, B G 4}=0.835\right)$ while presence of BG4 $\left(a_{B G 4, B Y 1}=0.208\right)$ has less pronounced competitive effect on the sorption of BY1 onto biosorbent. Competition coefficients obtained for binary system BY1-BG4 indicate that BG4 $\left(a_{B G 4, B Y 2}=0.186\right)$ was more significantly affected by the presence of BY2 $\left(a_{B Y 2, B G 4}=1.167\right)$. Finally, equations used in this work were represented by the three-dimensional biosorption isotherm surfaces.
\end{abstract}

Key words: cationic dyes, $R$. squarrosus, binary biosorption, equilibrium, isotherms

\section{Introduction}

Pollution of water sources by many organic contaminants over the past decades has become an issue of growing importance. Biosorption has become a well-established separation technique to remove diluted pollutants, offering the potential for regeneration, recovery and recycling of the adsorbed materials (McKAY et al., 2004).

Most of the research is engaged in biosorption of cationic dyes in single systems, but as wastewater from the dye manufacturing and textile finishing contains usually mixture of dye components, bigger accent on multicomponent adsorption systems should be put. When more than one species is present in the sorption system, the evaluation, interpretation and representation of sorption data become much more complicated (see e.g. LEE et al., 2004). But to provide additional information on the nature of biosortpion process, such as the fraction of adsorption sites being shared with each species, their relative affinities toward these sites, and the mutual interaction between the adsorbed species, is necessary to investigate the simultaneous sorption of two or more species (AKSU et al., 2009). 
Our previous study concerned with the sorption of cationic dyes Thioflavine $\mathrm{T}$ (BY1), Auramine O (BY2) and Malachite green (BG4) from single aqueous solutions onto moss biosorbent and Freundlich and Langmuir isotherm models were used to describe the equilibrium characteristics of monocomponent adsorption. The Freundlich isotherm was found to represent the measured sorption data of BG4, BY1 and BY2 well (REMENÁROVÁ et al., 2009). Within this context, the aim of our work was to study the sorption of cationic dyes from binary aqueous solutions by moss Rhytidiadelphus squarrosus. On the basis of the results obtained from single systems, Sheindorf-Rebuhn-Sheintuch (SRS) equation and extended model of Freundlich isotherm were chosen for analyzing equilibrium data and describing competitive effect of BG4, BY1 and BY2 in binary systems.

\section{Materials and methods}

\subsection{Biosorbent preparation}

A biomass of moss R. squarrosus used in this work was collected in High Tatras Mountains, Slovak Republic. To remove the impurities, the biomass was washed twice in deionized water, then oven-dried for $72 \mathrm{~h}$ at a maximum of $45^{\circ} \mathrm{C}$ to avoid the degradation of binding sites. After drying, the moss biomass was milled and sieved for particle size $<300 \mu \mathrm{m}$.

\subsection{Dyes}

Cationic dyes Malachite green (BG4, Basic green 4 - malachite green oxalate, $\mathrm{M}_{\mathrm{r}}$ 927, C.I. 42 000, Merck, D); Auramine O (BY2, Basic Yellow 2, $M_{\mathrm{r}}$ 304, C.I. 41000 , Aldrich, D) and Thioflavine T (BY1, Basic Yellow 1, $\mathrm{M}_{\mathrm{r}}$ 319, C.I. 49 005, Fluka, D) were used in sorption experiments (Fig. 1). The stock solutions of dyes were prepared in deionized water. Working solutions of desired concentrations were obtained by successive dilutions.

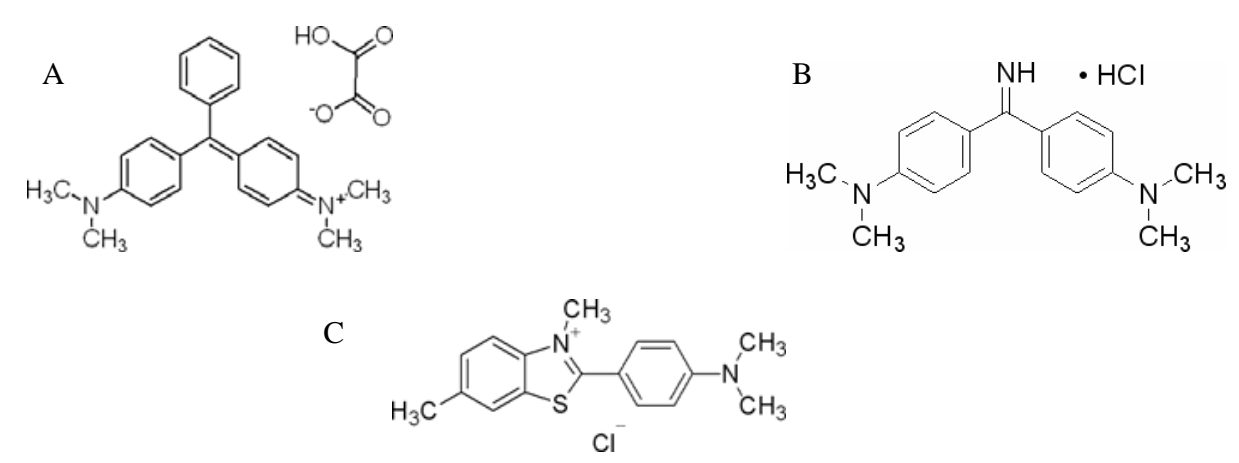

Fig. 1. Structure of the basic dyes: (A) malachite green, (B) auramine $\mathrm{O}$ and (C) thioflavine T. 


\subsection{Batch equilibrium sorption experiments in binary systems}

Batch biosorption experiments in binary systems BG4-BY1 and BG4-BY2 were carried out in series of solutions containing both dyes at initial concentrations within the range from 25 to $300 \mathrm{mg} / \mathrm{L}$ in the concentration ratio $2: 1,1: 1$ or $1: 2$. The $\mathrm{pH}$ was adjusted to 4.0 with $0.1 \mathrm{M} \mathrm{HCl}$. Biomass $(1 \mathrm{~g} / \mathrm{L}$, dw) was added, and the mixture in flasks was agitated on a reciprocal shaker $(120 \mathrm{rpm})$ for $4 \mathrm{~h}$ at $25^{\circ} \mathrm{C}$. The dye concentrations $\left(\mathrm{Ceq}_{B G 4}, \mathrm{Ceq}_{B Y 1}, \mathrm{Ceq}_{B Y 2}\right)$ in the solutions were determined spectrophotometrically (UV-VIS spectrophotometer Varian Cary 50). All experiments were performed in duplicate.

\subsection{Equilibrium modeling}

For description of sorption equilibrium in binary systems Sheindorf-RebuhnSheintuch (SRS) equation (competitive model derived from Freundlich isotherm) and extended model of Freundlich isotherm were used. To calculate the corresponding parameters of adsorption isotherms, non-linear regression analysis was performed by the NLSF (Origin's nonlinear least square fitter) using program MicroCal Origin 8.0 Professional (OriginLab Corporation, Northampton, USA) with automatic initialization of parameters and GraphPad PRISM 5.0 (GraphPad Software Inc., USA). The 3D sorption surfaces for each binary system were obtained by plotting the experimental dye equilibrium concentrations $C_{e q}$ on the $X$ and $Y$ axes, against the dye uptake $Q_{e q}$ on the $Z$ axis. The TableCurve 3D 4.0 (Systat Software, Inc., Chicago, USA) software was used for this purpose. The coefficient of determination $\left(R^{2}\right)$ and root mean squared error ( $R M S E$ ) were used to assess the goodness of the fit.

\subsection{Scanning electron microscopy (SEM)}

The surface structure of moss biosorbent was analyzing by scanning electron microscopy (SEM) using VEGA TESCAN microscope and software QUANTAX QX2 (version 1.6).

\section{Results and discussion}

Moss biomass, washed with water, dried at $45^{\circ} \mathrm{C}$ and milled, represents easily fractionable, well sedimenting material with a large specific surface area, suitable for biosorption of dissolved solutes. The surface of the particles $300-600 \mu \mathrm{m}$ fraction is shown in Fig. 2A and 2B.

Biosorption in multicomponent systems is rather complicated due to the possible interactions among the solutes. The behavior of each species in a multicomponent system depends strongly on the number and properties of other species present. Also the solution $\mathrm{pH}$, the physical and chemical properties of both the sorbent and sorbate significantly influenced the sorption process (AKSU and AKPINAR, 2000). 


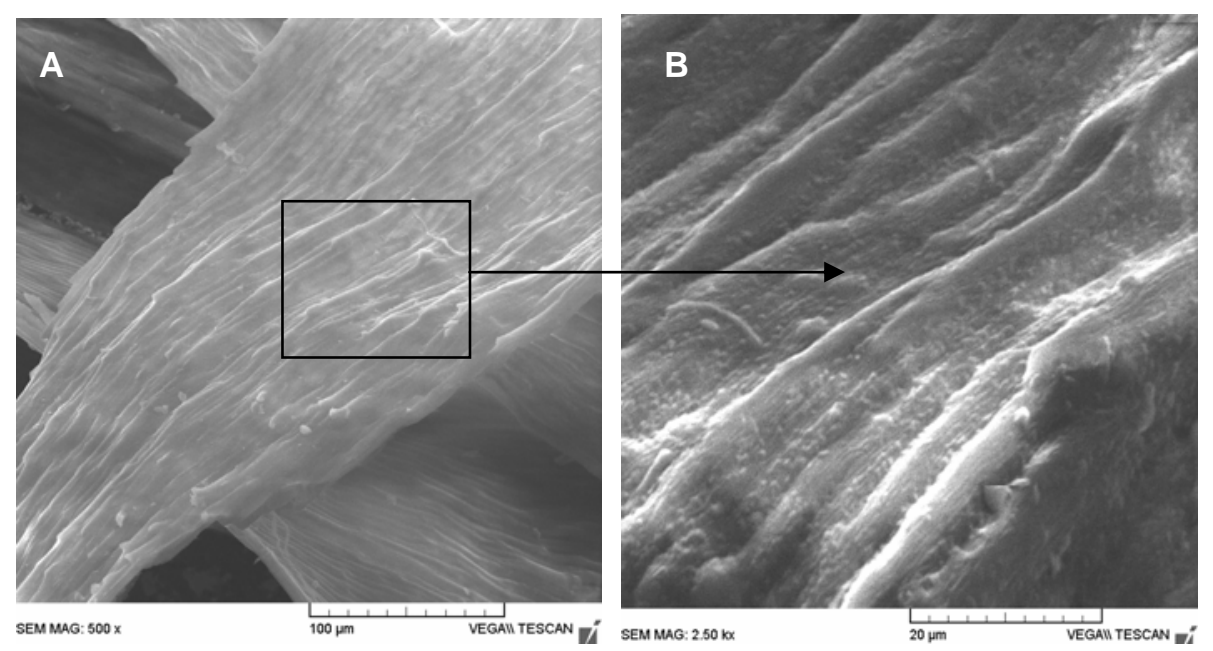

Fig. 2. SEM micrographs of biosorbent prepared from moss $R$. squarrosus. A) magnification 500×, B) magnification 2500×.

Sorption of dyes by R. squarrosus from binary system BG4-BY1 and BG4-BY2 at pH 4.0 is depicted in Fig. 3 and Fig. 4.
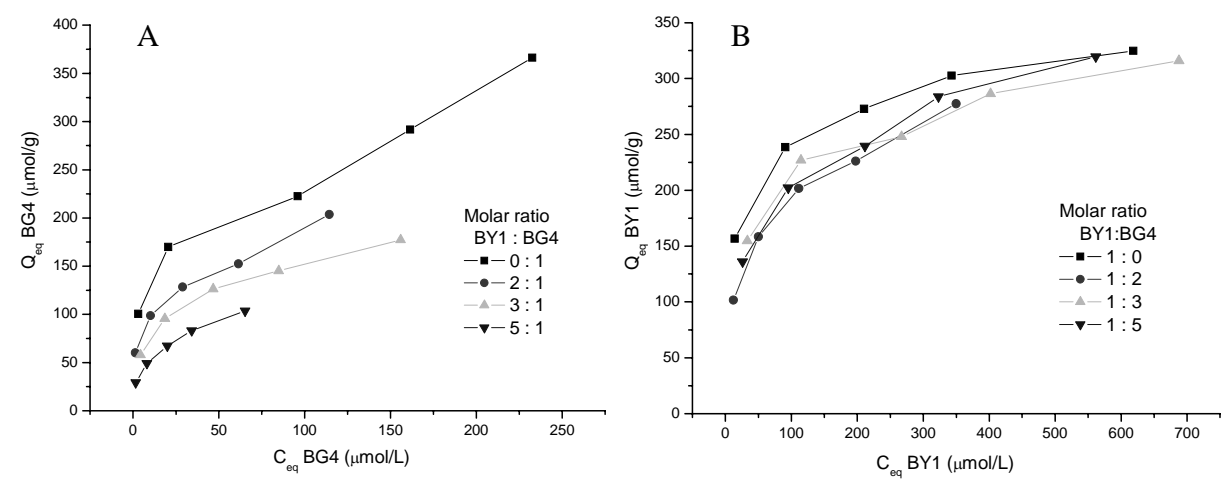

Fig. 3. Isotherms of the BG4 (A) and BY1 (B) biosorption by R. squarrosus $\left(1.0 \mathrm{~g} / \mathrm{L}\right.$, d.w.) at $25^{\circ} \mathrm{C}$ and $\mathrm{pH}$ 4.0 from binary system at different initial molar [BG4]:[BY1] ratios.

It is evident that sorption of dyes increased with the increasing of dyes concentration in solution. Sorption of BG4 from binary systems BG4-BY1 and BG4BY2 decreased with increasing concentration of BY1 (Fig. 3A) and BY2 (Fig. 4B) in solution. On the contrary, the presence of BG4 caused less pronounced decrease of both BY1 (Fig. 3B) and BY2 (Fig. 4A) sorption. This can be mainly attributed to the interactions between the basic dyes molecules on the biosorbent surface as reported TURABIK (2008).

Based on the literature review it is known that the most appropriate form to describe sorption equilibrium in binary systems is to adjust the experimental data to 
a mathematical model from which number of parameters can be obtained for quantitative interpretation of sorption equilibrium uptake (see e.g. SRIVASTAVA et al., 2009; ROMERA et al., 2008, TURABIK, 2008; TENG et al., 2009). In our previous study we determined that the sorption of dyes BG4, BY1 and BY2 from single systems by $R$. squarrosus was well described by Freundlich isotherm. Therefore we used the extended Freundlich model (FRITZ and SCHLUENDER, 1974) and Sheindorf-Rebuhn-Sheintuch (SRS) equation (SHEINDORF et al., 1981) (competitive model for binary systems derived from Freundlich isotherm) for description of equilibrium in binary systems. Parameters of Freundlich isotherm $K_{i}$ and $n_{i}$ are known from single system (REMENÁROVÁ et al., 2009).
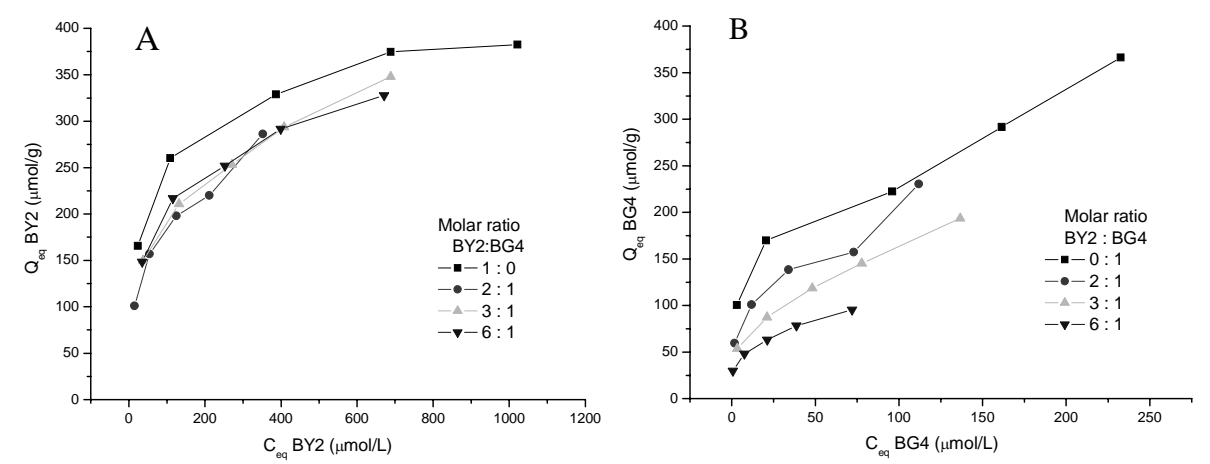

Fig. 4. Isotherms of the BY2 (A) and BG4 (B) biosorption by R. squarrosus (1.0 g/L, d.w.) at $25^{\circ} \mathrm{C}$ and $\mathrm{pH}$ 4.0 from binary system at different initial molar [BG4]:[BY2] ratios.

In 1974 Fritz and Schluender have discussed the extended form of the monocomponent Freundlich isotherm for defining sorption from the binary mixtures which can be written as follows:

$$
\begin{gathered}
Q_{e q, 1}=\frac{K_{1} C_{e q, 1}^{\left(1 / n_{1}\right)+x_{1}}}{C_{e q, 1}^{x_{1}}+y_{1} C_{e q, 2}^{z_{1}}} \\
Q_{e q, 2}=\frac{K_{2} C_{e q, i}^{\left(1 / n_{2}\right)+x_{2}}}{C_{e q, 2}^{x_{2}}+y_{2} C_{e q, 1}^{z_{2}}}
\end{gathered}
$$

where $K_{1}, K_{2}, n_{1}$ and $n_{2}$ are derived with the help of the mono-component isotherm. The rest of the parameters are determined using the non-linear regression analysis. The parameters $Q_{1}$ and $Q_{2}$ represent the amount of sorbed species 1 and 2 at equilibrium.

Also SHEINDORF et al. (1981) extended the Freundlich isotherm to multi-solute systems to derive a Freundlich-type multicomponent adsorption isotherm named Sheindorf-Rebuhn-Sheintuch (SRS) equation. The assumptions incorporated in the derivation are (1) each component individually follows the Freundlich isotherm and (2) for each component in the multi-component adsorption, an exponential distribution of adsorption energies exists, the distribution which is equivalent to the distribution in the single-component system. 
The SRS equations for component 1 and 2 in binary system are written:

$$
\begin{aligned}
& Q_{1}=K_{1} C_{1}\left(C_{1}+a_{12} C_{2}\right)^{n_{1}-1} \\
& Q_{2}=K_{2} C_{2}\left(a_{21} C_{1}+C_{2}\right)^{n_{2}-1}
\end{aligned}
$$

where $\alpha_{12}$ is the competition coefficient for the adsorption of component 1 in the presence of component 2 . The values for competition coefficient $\alpha_{12}$ range from zero (complete lack of competition) to values greater than zero for a high degree of competition. WU et al. (2002) and WEI and NAKATO (2006) laboured and successfully used this model to describe sorption of various contaminants from multisolute systems.

Both Freundlich-type isotherms were used to fit the experimental data. 3-D sorption isotherm surfaces of BG4-BY1 binary system predicted by the extended Freundlich model and SRS equation are shown in Fig. 5 and 6. Similar 3-D sorption isotherm surfaces of BG4-BY2 binary system predicted by the extended Freundlich model and SRS equation were obtained (not shown).
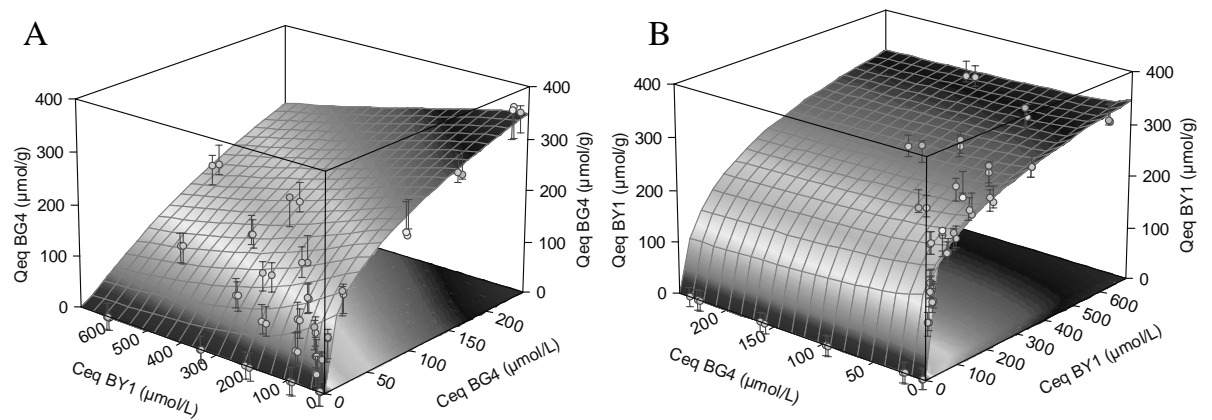

Fig. 5. 3-D sorption isotherm surfaces of BG4-BY1 binary system: (A) BG4 sorption ( $\mu \mathrm{mol} / \mathrm{g}$ ), (B) BY1 sorption $(\mu \mathrm{mol} / \mathrm{g}$ ). The surfaces are predicted by the extended Freundlich model (eq 1 and 2), the symbols represent experimental data obtained at $\mathrm{pH} 4.0$ and $25^{\circ} \mathrm{C}$. The vertical bars represent $95 \%$ confidence interval.
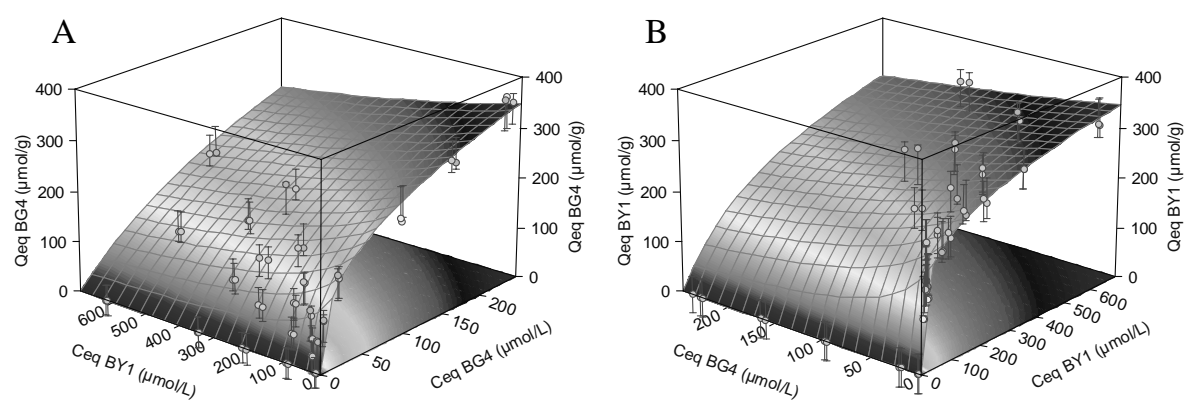

Fig. 6. 3-D sorption isotherm surfaces of BG4-BY1 binary system: (A) BG4 sorption ( $\mu \mathrm{mol} / \mathrm{g}$ ), (B) BY1 sorption $(\mu \mathrm{mol} / \mathrm{g}$ ). The surfaces are predicted by the SRS equation (eq 3 and 4 ), the symbols represent experimental data obtained at $\mathrm{pH} 4.0$ and $25^{\circ} \mathrm{C}$. The vertical bars represent $95 \%$ confidence interval. 
Parameters specified by the application of Freundlich-type models are presented in Table 1 and 2. By using of SRS model the competition coefficients $\alpha_{i j}$ were obtained. Higher competition coefficients values were estimated for sorption of BY1 $\left(a_{B Y I B G 4}=\right.$ $0.835 \pm 0.111$, Table 1$)$ and BY2 $\left(a_{B Y 2 B G 4}=1.167 \pm 0.139\right.$, Table 2$)$ in the presence of BG4, indicating that both BY1 and BY2 affect adsorption of BG4 markedly. On the other hand, values of competition coefficients obtained for sorption of BG4 in the presence of BY1 $\left(a_{B G 4 B Y 1}=0.208 \pm 0.015\right.$, Table 1$)$ and in the presence of BY2 $\left(a_{B G 4 B Y 2}=0.186 \pm 0.015\right.$, Table 2$)$ were smaller and indicate that sorption of BY1 and BY2 would be least affected by competitive interactions of BG4.

Values of $R^{2}$ and $R M S E$ are regarded as a measure of the goodness of fit of experimental data on the isotherms models. As can be seen from Table 1 a 2 high coefficients of determination $R^{2}$ and small values of $R M S E$ were obtained for both used models. This indicates that both models well describe the experimental biosorption data. To determine the model better describing experimental data we compared obtained experimental data $\left(Q_{\text {eq exp }}\right)$ with data calculated from models $\left(Q_{\text {eq cal }}\right)$. The analysis of the obtained scatter diagrams shows that experimental values were in a good agreement with values calculated from the extended Freundlich model (diagrams not shown). Agreement in case of the SRS equation was lower.

Table 1. Equilibrium parameters for BG4 and BY1 biosorption from the binary mixtures BG4-BY1 by moss $R$. squarrosus calculated from the extended Freundlich model and SRS model by non-linear regression analysis.

\begin{tabular}{|c|c|c|c|c|c|}
\hline \multirow{2}{*}{ Dye } & \multicolumn{3}{|c|}{ Extended Freundlich model } & \multirow{2}{*}{$R^{2}$} & \multirow{2}{*}{$\begin{array}{c}R M S E^{*} \\
(\mu \mathrm{mol} / \mathrm{g})\end{array}$} \\
\hline & $x_{i}$ & $y_{i}$ & $z_{i}$ & & \\
\hline BY1 & $0.858 \pm 0.179$ & $4.214 \pm 1.960$ & $0.304 \pm 0.141$ & 0.993 & 9.76 \\
\hline \multirow[t]{3}{*}{ BG4 } & $1.012 \pm 0.137$ & $0.025 \pm 0.013$ & $1.292 \pm 0.169$ & 0.983 & 13.22 \\
\hline & \multicolumn{3}{|c|}{ SRS model } & & \\
\hline & \multicolumn{2}{|l|}{$a_{B Y 1 B G 4}$} & $a_{B G 4 B Y 1}$ & & \\
\hline BY1 & \multicolumn{2}{|l|}{$0.835 \pm 0.111$} & 1 & 0.972 & 18.75 \\
\hline BG4 & \multicolumn{2}{|l|}{1} & $0.208 \pm 0.015$ & 0.977 & 14.98 \\
\hline
\end{tabular}

*Root mean squared error

Table 2. Equilibrium parameters for BG4 and BY2 biosorption from the binary mixtures BG4-BY2 by moss $R$. squarrosus calculated from the extended Freundlich model and SRS model by non-linear regression analysis.

\begin{tabular}{|c|c|c|c|c|c|}
\hline \multirow{2}{*}{ Dye } & \multicolumn{3}{|c|}{ Extended Freundlich model } & \multirow{2}{*}{$R^{2}$} & \multirow{2}{*}{$\begin{array}{l}R M S E^{*} \\
(\mu \mathrm{mol} / \mathrm{g})\end{array}$} \\
\hline & $x_{i}$ & $y_{i}$ & $z_{i}$ & & \\
\hline BY2 & $0.727 \pm 0.095$ & $4.126 \pm 1.227$ & $0.221 \pm 0.069$ & 0.995 & 8.94 \\
\hline \multirow[t]{3}{*}{ BG4 } & $1.140 \pm 0.150$ & $0.027 \pm 0.016$ & $1.340 \pm 0.179$ & 0.976 & 15.76 \\
\hline & \multicolumn{3}{|c|}{ SRS model } & & \\
\hline & \multicolumn{2}{|l|}{$a_{B Y 2 B G 4}$} & $a_{B G 4 B Y 2}$ & & \\
\hline BY2 & \multicolumn{2}{|l|}{$1.167 \pm 0.139$} & 1 & 0.971 & 21.32 \\
\hline BG4 & \multicolumn{2}{|l|}{1} & $0.186 \pm 0.015$ & 0.973 & 16.57 \\
\hline
\end{tabular}

*Root mean squared error 


\section{Conclusions}

In this work the biosorption of cationic dyes from binary solutions onto moss Rhytidiadelphus squarrosus was studied. Sorption data obtained from binary systems BY1-BG4 and BY2-BG4 were analyzed by Sheindorf-Rebuhn-Sheintuch (SRS) equation and extended model of Freundlich isotherm and presented in the form of 3D sorption isotherm surfaces. Based on the $R^{2}$ and $R M S E$ values both isotherms well described sorption of cationic dyes from binary systems. Higher competition coefficients values were estimated for sorption of BY1 and BY2 in the presence of BG4, indicating that both BY1 and BY2 affect adsorption of BG4 markedly. The influence of BG4 on sorption of BY1 and BY2 from binary systems was less pronounced.

It can be concluded that SRS equation and extended Freundlich model provide a suitable description of the experimental binary data. Prepared moss biosorbent may be used for individual and simultaneous removal of basic dyes from effluents.

\section{References}

AKSU, Z., ERTUGRUL, S., DÖNMEZ, G.: Single and binary chromium (VI) and Remazol Black biosorption properties of Phormidium sp. J. Hazard. Mat., 1168, 2009, 310-318.

AKSU, Z. AKPINAR, D.: Modelling of simultaneous biosorption of phenol and nickel(II) onto dried aerobic activated sludge. Sep. Purif. Technol., 21, 2000, 8799.

FRITZ, W., SCHLUENDER, E.U.: Simultaneous adsorption equilibria of organic solutes in dilute aqueous solutions on activated carbon. Chem. Eng. Sci., 29, 1974, 1279-1282.

LEE, H.S., SUH, J.H., KIM, I.B., YOON, T.: Effect of aluminum in two-metal biosorption by an algal biosorbent. Minerals Eng., 17, 2004, 487-493.

McKAY, G., ALLEN, S.J., PORTER, J.F.: Adsorption isotherm models for basic dye adsorption by peat in single and binary component systems. J. Colloid Interface Sci., 280, 2004, 322-33.

REMENÁROVÁ, L., PIPÍŠKA, M., HORNÍK, M., AUGUSTÍN, J.: Sorption of cationic dyes from aqueous solutions by moss Rhytidiadeplhus squarrosus: Kinetics and equilibrium studies. Nova Biotechnol., 9, 2009, 53-61.

ROMERA, E., GONZÁLEZ, F., BALLESTER, A., BLÁZQUEZ, M.L., MUÑOZ, J.A.: Biosorption of heavy metals by Fucus spiralis. Bioresour. Technol., 99, 2008, 684-4693.

SHEINDORF, CH., REBHUN, M., SHEINTUCH, M.: A Freundlich-type multicomponent isotherm. J. Colloid Interface Sci., 79, 1981, s.136-142.

SRIVASTAVA, V.CH., MALL, I.D., MISHRA. I.M.: Competitive adsorption of cadmium(II) and nickel(II) metal ions from aqueous solution onto rice husk ash. Chem. Eng. Process., 48, 2009, 370-379.

TENG, S.-X., WANG, S.-G., LIU, X.-W., GONG, W.-X., SUN, X.-F., CUI, J.-J., GAO, B.-Y.: Interaction between congo red and copper in a binary adsorption 
system: Spectroscopic and kinetic studies. Colloid. Surface. A: Physicochem. Eng. Aspects, 340, 2009, 86-92.

TURABIK, M: Adsorption of basic dyes from single and binary component systems onto bentonite: Simultaneous analysis of Basic Red 46 and Basic Yellow 28 by first order derivative spectrophotometric analysis method. J. Hazard. Mat., 158, 2008, 52-64.

WEI, Q., NAKATO, T.: Competitive adsorption of phenols on organically modified layered hexaniobate $\mathrm{K}_{4} \mathrm{Nb}_{6} \mathrm{O}_{17}$. Miscropor. Mesopor. Mat., 96, 2006, 84-92.

WU, CH.-H., KUO, CH.-Y., LIN, CH.-F., LO, S.-L.: Modeling competitive adsorption of molybdate, sulfate, selenate, and selenite using a Freundlich-type multicomponent isotherm. Chemosphere, 47, 2002, 283-292. 